\title{
Kinetic Energy Release and Position of Transition State During the Intramolecular Substitution of Ionized 2-Benzoyl Pyridines $\dagger$
}

\author{
Ralf Schubert and Hans-Friedrich Grützmacher \\ Fakultät für Chemie, Universität Bielefeld, Universitätsstraße, D-4800 Bielefeld 1, Germany
}

\begin{abstract}
The loss of substituents $X$ from molecular ions of ortho substituted 2-benzoyl pyridines has been investigated as a function of the dissociation energy of the $C-X$ bond. Comparison of unimolecular and collisional induced decompositions of the resulting $[M-X]^{+}$ions and reference ions arising from 3-hydroxypyrido[1,2a]indole shows that cyclic fragment ions are formed in every case by an intramolecular substitution reaction with the exception of the parent compound $(X=H)$, which gives rise to a mixture of $[M-H]^{+}$ions with different structures. The heat of formation of the cyclic ion has been estimated experimentally and by calculation using thermochemical data, and from this value and the appearance energies, the activation energies of the reverse reactions have been evaluated for the different reaction systems. Measurement of the kinetic energy release during the substitution reactions shows that only part of the reverse activation energy is released as kinetic energy. The energy partitioning quotient varies from 0.37 to 0.08 depending on the dissociation energy of the $\mathrm{C}-\mathrm{X}$ bond or the reaction enthalpy. A sudden change in the energy partitioning quotient is observed with increasing exothermicity of the reaction, paralleling the behaviour of similar reaction systems. These results are interpreted as a demonstration of the influence of the variation of transition state position on the energy partitioning quotient.
\end{abstract}

It has been shown recently ${ }^{2}$ that the partitioning of the excess potential energy of the transition states (or the activation energy of the reverse reactions $\varepsilon_{r}^{\neq}$) between the kinetic energy $T$, released during the reaction, and the internal energy $\varepsilon^{*}$ of the products during the loss of ortho substituents from the molecular ions of substituted benzalacetones depends strongly and systematically on the thermochemistry of the reaction or the position $^{3}$ of the transition state on the reaction coordinate. Thus it appears that an investigation of the variation of the kinetic energy release and the energy partitioning quotient $q=T / \varepsilon_{r}^{\neq}$with structural changes of the reactant ions gives some insight into fundamental properties of elementary reactions of organic ions, which will be useful in testing mechanistic models of organic chemistry and linking them more closely to physical theories of chemical reactions. The loss of substituents from molecular ions of benzalacetones with formation of 2-methylbenzpyrylium ions ${ }^{4}$ can be regarded as an intramolecular aromatic substitution reaction, ${ }^{5}$ a well known reaction in organic chemistry. As a further example of this type of reaction the results of a detailed investigation of the loss of ortho substituents from the molecular ions of substituted 2-benzoyl pyridines 1a-1g (Scheme 1) are reported.

The decomposition of the molecular ions of $\mathbf{1 a - 1 g}$ occurs by the three competing fragmentation pathways $\mathrm{A}-\mathrm{C}$ shown in Scheme 1. Compound 1a exhibits large peaks due to $[\mathrm{M}-\mathrm{H}]^{+}$and $[\mathrm{M}-\mathrm{CO}]^{+\cdot}$ ions in its $70 \mathrm{eV}$ mass spectrum, which are absent or of much lower relative abundance in the $70 \mathrm{eV}$ mass spectra of

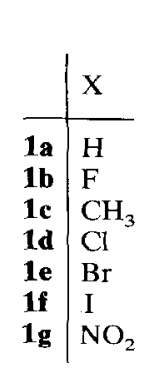<smiles>[Y]c1ccccc1C(=O)c1ccccn1</smiles><smiles>O=C(c1ccccc1)c1cccnc1</smiles>

lc $\mathrm{CH}_{3}$

le $\mathrm{Br}$

1f 1 I<smiles>[2H]c1c([2H])c([2H])c(C(=O)c2ccccn2)c([2H])c1[2H]</smiles><smiles>O=C(c1ccccc1)c1ccncc1</smiles>

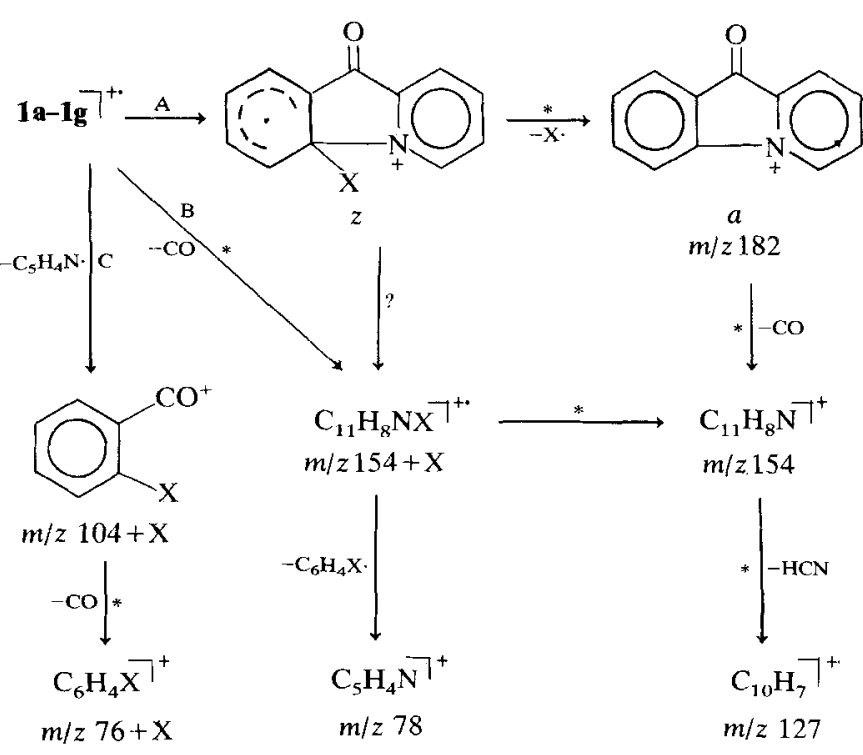


Table 1. Relative intensities $(\% \mathrm{~B})$ in the $70 \mathrm{eV}$ mass spectra of substituted 2-benzoyl pyridines $1 \mathrm{a}-1 \mathrm{~g}$

\begin{tabular}{|c|c|c|c|c|c|c|c|}
\hline Ion $\mathrm{m} / \mathrm{z}$ & 1a & 1b & 1c & 1d & 18 & if & $1 \mathrm{~g}$ \\
\hline$[\mathrm{M}]^{+\cdot}$ & 22 & 23 & 24 & $<1$ & $<1$ & $<1$ & $<0.1$ \\
\hline$[\mathrm{M}-\mathrm{H}]^{+}$ & $\{35$ & 24 & 12 & 3 & 2 & $<1$ & - \\
\hline$[\mathrm{M}-\mathrm{X}]^{+}$ & 35 & 17 & 17 & 100 & 100 & 100 & 100 \\
\hline$\left[\mathrm{M}-\mathrm{CO}^{+\cdot}\right.$ & 68 & 92 & 33 & 2 & 1 & $<1$ & - \\
\hline$[\mathrm{M}-\mathrm{CO}-\mathrm{H}]^{+}$ & 26 & 27 & 100 & 1 & - & - & - \\
\hline$\left[\mathrm{M}-\mathrm{C}_{5} \mathrm{H}_{4} \mathrm{~N}\right]^{+}$ & 66 & 100 & 36 & 32 & 24 & 14 & 4 \\
\hline$\left[\mathrm{M}-\mathrm{C}_{5} \mathrm{H}_{4} \mathrm{~N}-\mathrm{CO}\right]^{+}$ & 100 & 68 & 61 & 36 & 29 & 21 & - \\
\hline 155 & $68^{b}$ & - & - & 2 & $29^{e}$ & 1 & 2 \\
\hline 154 & $26^{\mathrm{c}}$ & 3 & 2 & 16 & 11 & 7 & 4 \\
\hline 153 & 2 & 3 & - & 2 & 3 & 4 & 5 \\
\hline 152 & 1 & 2 & - & 1 & 1 & 2 & 2 \\
\hline 128 & 4 & - & - & 3 & 4 & 6 & 7 \\
\hline 127 & 7 & 2 & 1 & 8 & 10 & 16 & 17 \\
\hline 126 & 2 & 1 & - & 2 & 3 & 5 & 7 \\
\hline 115 & 1 & - & 2 & - & - & - & 5 \\
\hline 106 & 6 & - & - & - & - & - & 7 \\
\hline 105 & $66^{d}$ & - & - & - & - & - & 3 \\
\hline 101 & 1 & - & - & 1 & 2 & 3 & 4 \\
\hline 78 & 20 & 17 & 7 & 6 & 9 & 13 & 58 \\
\hline 77 & $100^{e}$ & 2 & 1 & 9 & 5 & 8 & 14 \\
\hline 76 & 7 & 4 & - & 5 & 10 & 15 & 34 \\
\hline 75 & 4 & 33 & - & 22 & 9 & 4 & 9 \\
\hline 74 & 3 & 4 & - & 3 & - & 2 & 5 \\
\hline 65 & - & - & 30 & - & - & - & 2 \\
\hline 64 & 1 & - & 1 & - & - & - & 4 \\
\hline 63 & 3 & 2 & 2 & 2 & 1 & 2 & 7 \\
\hline 52 & 9 & 8 & 3 & 4 & 2 & 2 & 13 \\
\hline 51 & 55 & 26 & 6 & 16 & 8 & 10 & 59 \\
\hline 50 & 15 & 9 & 1 & 9 & 4 & 7 & 25 \\
\hline
\end{tabular}

${ }^{a}$ Corrected for isotopes; all ions above $\mathrm{m} / \mathrm{z} 50$ and $>1 \% \mathrm{~B}$ are given.

${ }^{b}[\mathrm{M}-\mathrm{CO}]^{+} . \quad{ }^{c}[\mathrm{M}-\mathrm{CO}-\mathrm{H}]^{+} . \quad{ }^{\mathrm{d}}\left[\mathrm{M}-\mathrm{C}_{5} \mathrm{H}_{4} \mathrm{~N}\right]^{+} . \quad{ }^{e}\left[\mathrm{M}-\mathrm{C}_{5} \mathrm{H}_{4} \mathrm{~N}-\right.$ COJ'.

benzophenone, 3-benzoyl pyridine (2) and 4-benzoyl pyridine (3). ${ }^{6}$ Hence, it has been assumed ${ }^{7}$ that 1 a forms $[\mathrm{M}-\mathrm{H}]^{+}$ions with the cyclic pyridinium ion structure $a$ by an attack of the $\mathrm{N}$ atom of the pyridine nucleus on the ortho position of the phenyl group, probably occurring through the intermediate ion $z$. Competing with the loss of an $\mathrm{H}$ atom (or the substituent $X$ at the phenyl group) from the molecular ions are the formation of (substituted) benzoyl ions by $\alpha$-cleavage $^{1}$ and the loss of CO. The latter fragmentation has also been observed in the mass spectra of related heteroaromatic ketones. ${ }^{7}$

The $70 \mathrm{eV}$ mass spectra of the ortho substituted 2-benzoyl pyridines $\mathbf{1 b - 1 g}$ (Table 1) are comprised mainly of fragment ions formed by the same three reaction paths. Only the nitro derivative $1 \mathrm{~g}$ shows additional fragmentations due to the known reactions of a nitro group. The relative abundances of the molecular ions and the fragment ions arising from the three reaction paths are given in Table 2 . No large influence of the ortho substituents on the abundance of ions formed by initial loss of $\mathrm{CO}$ are observed. However, the intensities of the $[\mathrm{M}-\mathrm{X}]^{+}$ions formed by loss of the ortho substituents increase and those of the molecular ions and products of the $\alpha$-cleavage decrease considerably with decreasing strength of the bond to the substituent. This is expected if the [M$\mathrm{X}^{+}$ions are formed by an intramolecular substitution reaction within the molecular ions. Furthermore, the activation energy $\varepsilon_{h}^{\neq}$for the formation of the $[M-X]^{+}$
Table 2. Relative contributions" of molecular ions and ions formed by fragmentation pathways $A, B$ and $C$

\begin{tabular}{lrrrr}
\hline & \multicolumn{4}{c}{ Fragmentation pathway } \\
& {$[\mathrm{M}]^{+-}$} & \multicolumn{1}{c}{$\mathrm{A}$} & \multicolumn{1}{c}{$\mathrm{B}$} & $\mathrm{C}$ \\
1a & 4.5 & 12.1 & 23.4 & 60.0 \\
1b & 4.8 & 10.7 & 28.8 & 55.7 \\
1c & 5.9 & 9.7 & 43.1 & 41.4 \\
1d & $<0.1$ & 47.4 & 7.1 & 45.5 \\
1e & $<0.1$ & 56.9 & 5.5 & 37.6 \\
1f & $<0.1$ & 60.8 & - & 36.3 \\
1g & $\ll 0.1$ & 52.7 & 2.9 & 47.3 \\
\hline a In \% of total ions formed.
\end{tabular}

ions is only $0.5-1.1 \mathrm{eV}$ (Table 5). Hence, a bond forming process clearly must be involved in the formation of the $[M-X]^{+}$ions besides cleavage of the bond to the substituent.

Nevertheless, two observations show that the [M$\mathrm{X}]^{+}$ions are not formed by a direct displacement of the ortho substituent. First, the $70 \mathrm{eV}$ mass spectrum of 2-pentadeuterobenzoyl pyridine (4) shows peaks of $[\mathrm{M}-\mathrm{H}]^{+}$and $[\mathrm{M}-\mathrm{D}]^{+}$ions in a ratio of $1: 0.6-0.7$ and not a specific loss of $D$ from the pentadeuterated phenyl group. The $[\mathrm{M}-\mathrm{H}]^{+} /[\mathrm{M}-\mathrm{D}]^{+}$ratio is close to the value 0.8 expected for a statistical distribution of $\mathrm{H}$ and $\mathrm{D}$ atoms in the molecular ions prior to the fragmentation. No positional $\mathrm{H} / \mathrm{D}$ exchange occurs in the molecular ions, however, since the benzoyl ions in the mass spectrum of $\mathbf{4}$ completely retain their original five $D$ atoms. Thus, the $H / D$ exchange must occur during the formation of the $[\mathrm{M}-\mathrm{H}]^{+}$and $[\mathrm{M}-\mathrm{D}]^{+}$ ions as a specific property of this reaction path.

Second, substituents at the meta and para positions of the phenyl group of the molecular ions are also lost, although to a much lesser extent. ${ }^{\circ}$ The activation energies for these processes are nearly equal to that for loss of the ortho substituent; hence the low abundances of the $[\mathrm{M}-\mathrm{X}]^{+}$ions in the mass spectra of meta and para substituted derivatives must be due to extremely small frequency factors. Similar effects have been observed in the mass spectra of meta and para substituted benzalacetones ${ }^{4}$ and can be explained by the formation of $z$ as an intermediate in the substitution reaction. $z$ isomerizes by a 'ring-walk' mechanism of the $\mathrm{H}$ atom, which gives rise either to the loss of the substituents at the meta and para positions, respectively, after the $\mathrm{H}$ atom has arrived at the proper position, or to positional exchange of $H$ and $D$ atoms in $z$ formed from 4 prior to decomposition. In the latter case a large isotope effect is observed discriminating against loss of $\mathrm{D}$. The $[\mathrm{M}-\mathrm{H}]^{+} /[\mathrm{M}-\mathrm{D}]^{+}$ ratio increases from $0.6-0.7$ in the $70 \mathrm{eV}$ mass spectrum to 2.2 in the $11 \mathrm{eV}$ (nominal) mass spectrum and to 11.4 for metastable molecular ions decomposing in the second field free region (2nd FFR) of a Varian $311 \mathrm{~A}$ mass spectrometer.

\section{Structure of the $[M-X]^{+}$ions}

The crucial point in mass spectrometric investigations of the type discussed in this paper is a knowledge of the structure of the reaction products and of their 


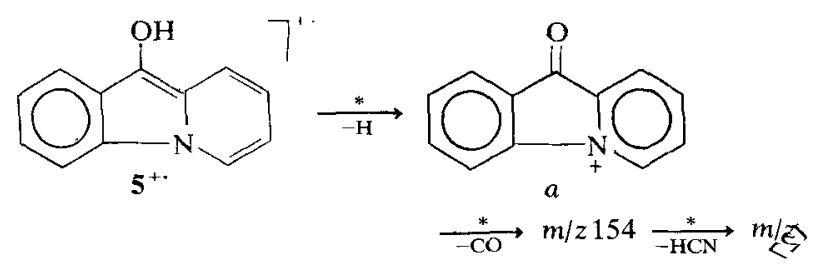

Scheme 2

heats of formation. Although the structure of the cyclic pyridinium ions a (Scheme 1) seems to be $a$ priori very likely for the $[\mathrm{M}-\mathrm{X}]^{+}$ions in view of the experimental facts, it is important to obtain additional independent experimental evidence about their structure(s). The problem of structure determination of organic ions in the gas phase of a mass spectrometer is still not satisfactorily solved. The best one can do is to look at unimolecular ${ }^{9}$ metastable ion (MI) spectra and collisional activation ${ }^{10}$ (CA) spectra of selected ion species. However, the MI spectra are known to depend not only on the structures of the ions but also on their internal energy, and the CA technique appears to be rather crude compared with the spectroscopic methods available for a structure determination of neutral species.

The MI and CA spectra of the $[\mathrm{M}-\mathrm{X}]^{+}$ions in the $70 \mathrm{eV}$ mass spectra of $\mathbf{1 a - 1 g}$ and related compounds are given in Tables 3 and 4 . The $[\mathrm{M}-\mathrm{H}]^{+}$ions in the $70 \mathrm{eV}$ mass spectrum of 3-hydroxypyrido[1,2-a]indole (5) are used as reference ions. Compound $\mathbf{5}$ arises from 1 a by a photochemical reaction ${ }^{11}$ and the $[\mathrm{M}-$ $\mathrm{H}]^{+}$ions give rise to the base peak in its $70 \mathrm{eV}$ mass spectrum. Above $\mathrm{m} / \mathrm{z} 80$ there are only two other peaks at $m / z 154$ and $m / z 127$ with relative intensities $>10 \%$, besides the molecular ion peak. The ions $\mathrm{m} / \mathrm{z}$ 154 and $m / z \quad 127$ are formed by subsequent loss of $\mathrm{CO}$ and $\mathrm{HCN}$ from the $[\mathrm{M}-\mathrm{H}]^{+}$ions, and no peaks for ions formed by the other two fragmentation paths are observed with significant intensities. This excludes an isomerization of the molecular ions of 5 to those of 1 a prior to fragmentation and makes it highly probable that the $[\mathrm{M}-\mathrm{H}]^{+}$ions of $\mathbf{5}$ retain the original cyclic structure.

All ions $m / z 182$ listed in Table 3 show signals due to loss of $\mathrm{CO}$ and loss of $\mathrm{CO}+\mathrm{HCN}$ (to $\mathrm{m} / z 154$ and to $m / z 127$, respectively) in their MI spectra, with the

Table 3. MI spectra of ions $[\mathrm{M}-\mathrm{X}]^{+}$in the $70 \mathrm{eV}$ mass spectra of substituted 2-benzoyl pyridines and related compounds

\begin{tabular}{|c|c|c|c|c|c|}
\hline & \multicolumn{2}{|c|}{ m/z 154} & \multicolumn{2}{|c|}{$\mathrm{m} / \mathrm{z} 127$} & \multirow[b]{2}{*}{$i_{154} / i_{127}$} \\
\hline & Rel. int. & $T_{50}^{a}$ & Rel int. & $T_{50}{ }^{2}$ & \\
\hline $1 \mathrm{a}$ & 93.6 & 76 & 6.4 & 123 & 14.6 \\
\hline $1 b$ & 83.9 & 107 & 16.1 & 93 & 5.2 \\
\hline $1 c$ & 79.6 & 159 & 20.4 & 105 & 3.9 \\
\hline $1 d$ & 77.7 & 230 & 22.3 & 103 & 3.5 \\
\hline $1 \mathrm{e}$ & 77.6 & 240 & 22.4 & 98 & 3.5 \\
\hline $1 f$ & 75.8 & 264 & 24.2 & 106 & 3.1 \\
\hline 19 & 75.1 & 261 & 24.9 & 108 & 3.0 \\
\hline 2 & 98.4 & 76 & 1.6 & - & 62 \\
\hline 3 & $67.0^{\mathrm{b}}$ & - & - & - & - \\
\hline $4^{c}$ & $98.5^{\mathrm{e}}$ & 78 & $1.5^{f}$ & - & 一 \\
\hline $4^{d}$ & $92.5^{\mathrm{e}}$ & 76 & $7.5^{t}$ & - & - \\
\hline 5 & 76.6 & 235 & 23.3 & 103 & 3.3 \\
\hline
\end{tabular}

a In meV. ${ }^{b} \mathrm{~m} / \mathrm{z} 10433 \% .{ }^{\circ}[\mathrm{M}-\mathrm{H}]^{+} \mathrm{m} / \mathrm{z} 187$

[M-D $]^{i} \mathrm{~m} / \mathrm{z} 186,{ }^{\mathrm{e}}$ Loss of CO. ${ }^{\mathrm{L}}$ Loss of HCN and DCN.
Table 4. CA mass spectra" of ions $[M-X]^{+}$in the $70 \mathrm{eV}$ mass spectra of 2-benzoyl pyridines and related compounds

\begin{tabular}{ccccccc}
\hline$m / z$ & $1 \mathbf{a}$ & $1 \mathbf{b}$ & $\mathbf{1 d}$ & $\mathbf{1 c}$ & ff & 5 \\
$181^{\mathrm{b}}$ & $(27)$ & $(30)$ & $(29)$ & $(27)$ & $(18)$ & - \\
$164-166$ & 2 & 2 & 1 & 1 & 1 & 3 \\
$154^{\mathrm{b}}$ & $(59)$ & $(50)$ & $(46)$ & $(50)$ & $(35)$ & $(23)$ \\
$139-140$ & 2 & 3 & 3 & 3 & 2 & 2 \\
$127^{b}$ & $(56)$ & $(53)$ & $(51)$ & $(54)$ & $(42)$ & $(41)$ \\
$113-115$ & 5 & 4 & 4 & 4 & 3 & 3 \\
101 & 19 & 15 & 15 & 13 & 12 & 12 \\
$86-89$ & 11 & 7 & 7 & 8 & 6 & 5 \\
$74-78$ & 31 & 39 & 37 & 37 & 34 & 49 \\
$62-63$ & 10 & 10 & 11 & 10 & 12 & 9 \\
51 & 13 & 15 & 17 & 17 & 21 & 18 \\
39 & 3 & 3 & 5 & 5 & 6 & - \\
28 & 1 & 1 & 1 & 1 & 2 & -- \\
\hline
\end{tabular}

Rel. int. in \% total fragment ions. ${ }^{b}$ Not used for normalization, but peak forms also indicate contributions from $\mathrm{m} / \mathrm{z} 153$ and $\mathrm{m} / \mathrm{z} 126$, respectively.

exception of the $[\mathrm{M}-\mathrm{H}]^{+}$ions $m / z \quad 182$ from 3. The metastable $[\mathrm{M}-\mathrm{H}]^{+}$ions of $\mathbf{3}$ fragment by loss of $\mathrm{CO}$ (to $m / z 154$ ) and of $\mathrm{C}_{5} \mathrm{H}_{4} \mathrm{~N}$ (to $\mathrm{m} / z$ 104) in the ratio of $67 / 33$, and thus are certainly of a different structure with respect to the other $m / z 182$ ions. The intensity ratio 3,4 of the two signals $m / z \quad 154 / m / z \quad 127$ is the same within the limits of error for the $[\mathrm{M}-\mathrm{H}]^{+}$ions of 5 and the $[M-X]^{+}$ions of $1 \mathbf{c}-1 \mathrm{~g}$, proving identical structures $a$ and similar internal energies for these ions. This is corroborated by values of the kinetic energy release $T_{50}$, measured at half height of the signals, of the two fragmentation reactions of the ions $m / z \quad 182$ (Table 3) of $245 \pm 20 \mathrm{meV}(\mathrm{m} / z$ 155) and $104 \pm 10 \mathrm{meV}\left(\mathrm{m} / z\right.$ 127). Only the $T_{50}$ value $159 \mathrm{meV}$ observed for loss of $\mathrm{CO}$ from the $[\mathrm{M}-\mathrm{X}]^{+}$ions of 1c is too small; this, however, may be due to a smaller amount of internal energy available for fragmentations of these metastable ions $m / z 182$.

The intensity ratio $m / z \quad 154 / m / z \quad 127$ in the MI spectra of ions $m / z 182$ of $\mathbf{1 b}$ and $\mathbf{1 a}$ increases to 5.2 and 14.6 respectively, and there is a further large increase in this intensity ratio to $>50$ for ions $\mathrm{m} / \mathrm{z} 182$ from 2. The $T_{50}$ value $\mathrm{m} / z \quad 127$ of $93 \mathrm{meV}$ for ions $\mathrm{m} / \mathrm{z} 182$ from $\mathbf{1 b}$ is within the range of values observed for ions $a$ although at the lower limit. The $T_{50}$ value $\mathrm{m} / \mathrm{z} 154$ of $103 \mathrm{meV}$, however, is certainly too small to be explained by the error of measurement. Again this effect can be ascribed to a reduced amount of internal energy in the $m / z 182$ ions of $\mathbf{1 b}$, which have to be formed by cleavage of a strong carbonfluorine bond. Obviously the amount of internal energy is sufficient to liberate the small kinetic energy associated with formation of ions $m / z 127$, but is not large enough to allow for the large kinetic energy release during loss of $\mathrm{CO}$. As one would expect the appearance energy for loss of $\mathrm{CO}$ from ions $\mathrm{m} / \mathrm{z} 182$ to be somewhat smaller than that for a combined loss of $\mathrm{CO}$ and HCN, a small amount of internal energy in the ions $m / z 182$ should discriminate against the latter process, thus also explaining the increased intensity ratio $m / z 154 / m / z \quad 127$ in the MI spectra of $m / z 182$ from $\mathbf{1 b}$.

This type of argument cannot be used to explain the deviations in the MI spectra of $m / z 182$ from 19 , 


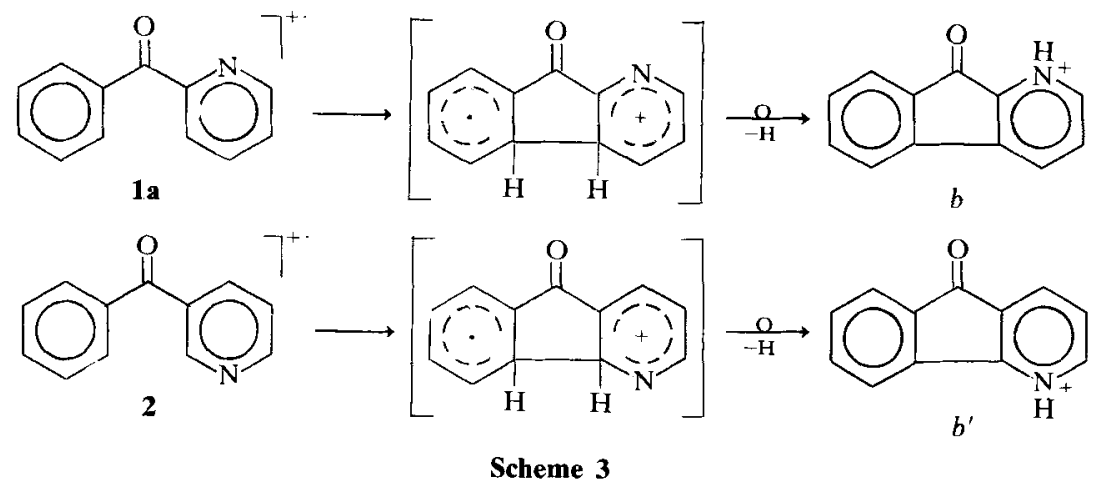

however. The order of $T_{50}$ values $\mathrm{m} / z 154$ and $\mathrm{m} / \mathrm{z}$ 127 is reversed and the $T_{50}$ value $m / z 154$ agrees well with that observed for ions $m / z 182$ from 2 . Hence, it follows that the metastable $[\mathrm{M}-\mathrm{H}]^{+}$ions $m / z 182$ in the mass spectrum of 19 represent at least a mixture of structures with the dominant component being similar in structure to the metastable $[\mathrm{M}-\mathrm{H}]^{+}$ions of 2 . These ions $b$ are probably formed by a $\mathrm{C}-\mathrm{C}$ linkage between both aromatic rings in $\mathbf{1 a}$ or $\mathbf{2}$, followed by migration of one $\mathrm{H}$ atom to the $\mathrm{N}$ atom of the pyridine group and by loss of another $\mathrm{H}$ atom (Scheme 3 ).

The CA spectra of the $m / z 182$ ions from 1a-1f and 5 (Table 4) have been obtained through activation of the ions by collisions with molecules of the target gas (air) in the 2nd FFR preceding the electrostatic analyser of a VG ZAB-2F mass spectrometer. The signals in the CA mass analysed ion kinetic energy (MIKE) spectra are rather broad due to kinetic energy release and to overlap of adjacent signals. The intensity distribution and the shapes of the peaks are very similar throughout the series of $m / z 182$ ions, showing only a small trend in the relative intensities of the daughter ions $m / z 101$ and $m / z 51$. While this result agrees well with the conclusions drawn from the MI spectra of the $\mathrm{m} / \mathrm{z} 182$ ions from $\mathbf{1 b}-\mathbf{1 g}$ and $\mathbf{5}$ and confirms the structure $a$ for these ions, it seems suspect with regard to ions $m / z 182$ from $1 \mathrm{a}$. The good agreement between the CA MIKE spectra of ions $m / z 182$ from 1a and from the other compounds, in spite of the difference in the MI spectra, indicates that either most of the stable $\mathrm{m} / z 182$ ions from $1 \mathrm{a}$ which are activated by collisions for fragmentations are of structure $a$ and the contributions of ions $b$ and other isomers are swamped out in the CA spectra, or that the CA technique is not very sensitive to the structural differences between ions $a$ and $b$.

CA spectra obtained using $B / E$ linked scans and Ist FFR collisions with helium for compounds $\mathbf{1 a}$ and $\mathbf{2}$ at $70 \mathrm{eV}$ electron energy are not very different, although these ions are certainly not of structure $a$ in the case of 2 . The product ions $m / z \quad 181$ and 153 are more abundant in the CA spectra of $m / z 182$ from 1a, and this difference is more distinct in spectra obtained with $15 \mathrm{eV}$ electron energy.

In summary, the results of the MI and CA spectra show clearly that the $[\mathrm{M}-\mathrm{H}]^{+}$ions of 5 and the $[\mathrm{M}-\mathrm{X}]^{+}$ions of $\mathbf{1 b - 1 g}$ are of the same structure, corresponding to $a$ without much doubt. The structure of the $[\mathrm{M}-\mathrm{H}]^{+}$ions from $\mathbf{1 a}$ remains uncertain however. The $m / z 182$ ions from this compound most probably represent a mixture of structurally different ions, including ions $a$.

\section{Energetics of the formation of the $[M-X]^{+}$ions}

The heat of formation $\Delta H_{f}$ of organic ions in the gas phase can be deduced from determinations of the appearance energies $\mathrm{A}\left(\mathrm{F}^{+}\right)$of these ions or from calculations including increments and relevant thermochemical data like ionization energies $\mathrm{I}(\mathrm{M})$ and proton affinities (PA). Unfortunately, the results of both methods are not very accurate, so that at present the best one can hope is to arrive at a set of 'selfconsistent data'. The appearance energy $\mathrm{A}\left(\mathrm{F}^{+}\right)$does not correspond to the enthalpy of reaction $\Delta \mathrm{H}_{\mathrm{R}}^{+}$of a mass spectrometric fragmentation, but to the potential energy of the transition state of that reaction plus a small amount of non-fixed energy (kinetic shift). Thus, only 'apparent' heats of formation $\Delta H_{\mathrm{f}}^{\prime}$ are obtained by use of Eqn (1), including the activation energy of the reverse reaction $\varepsilon_{\mathrm{r}}^{*}$. A part of the contribution of $\varepsilon_{\mathrm{r}}^{\neq}$can be corrected for by the amount released as the maximum kinetic energy $T_{B}$ in the fragments. However, it is not known a priori whether the total $\varepsilon_{\mathrm{r}}^{\neq}$or only a part of it is released as $T_{\mathrm{B}}$.

The appearance energies $\mathrm{A}\left(182^{+}\right)$of the ions $\mathrm{m} / \mathrm{z}$ 182 from 1a-1g and $\mathbf{5}$ are listed in Table 5, together with the heats of formation of the neutral precursor molecules, calculated by increments, ${ }^{12}$ their ionization energies $I(M)$, the heats of formations of the radicals lost $^{12 \mathrm{~b}}$ and the maximum kinetic energy $T_{\mathrm{B}}$ released during the reactions. The intensities of the molecular ions of 1d-1g are too small for a reliable determination of $I(M)$ by measuring ionization efficiency curves. The $\mathrm{I}(\mathrm{M})$ of these compounds have been estimated from the $\mathrm{I}(\mathrm{M})$ of the corresponding meta and para substituted derivatives and the correlation of the I(M) of substituted 2-benzoyl pyridines with $\sigma_{\mathrm{IP}}^{+}$values. ${ }^{8}$ To obtain a 'maximum' value of $T$, the signals in the MIKE spectrum have been approximated by triangles (or trapezia in case of flat-topped signals) and the width of the peaks has been measured at the base lines. The reproducibility of these $T_{B}$ values is $<$ $\pm 10 \%$.

These data have been used to calculate the activation energy of the forward reaction $\varepsilon_{\mathrm{h}}^{\neq}$, the apparent and corrected heats of formation of the ions $m / z 182$, $\Delta H_{f}^{\prime}\left(182^{+}\right)$and $\Delta H_{f}^{\prime}(182)_{\text {corr }}$ and the enthalpy of reaction $\Delta H_{\mathrm{R}}^{+}$, starting from the molecular ions, according 
Table 5. Thermochemical data for the fragmentation of substituted 2-benzoyl pyridines

\begin{tabular}{|c|c|c|c|c|c|c|c|c|c|}
\hline & $\Delta H_{f}(M)$ & $\Delta H_{f}(X)$ & I(M) & $\Delta H_{f}\left(M^{+\cdot}\right)$ & $A\left(182^{+}\right)$ & $\varepsilon_{h}^{*}$ & $\Delta H_{f}^{\prime}\left(182^{+}\right)$ & $T_{B}$ & $\Delta H_{f}^{\prime}\left(182_{\mathrm{corr}}^{\prime}\right)$ \\
\hline $1 a$ & 100 & 218.0 & 874 & 975 & 962 & 88 & 845 & 46 & 799 \\
\hline $1 b$ & -88 & 76.6 & 879 & 791 & 979 & 100 & 816 & 13 & 803 \\
\hline $1 c$ & 71 & 142.3 & 841 & 912 & 937 & 96 & 866 & 46 & 820 \\
\hline $1 d$ & 75 & 120.9 & 866 & 941 & 925 & 58 & 879 & 13 & 866 \\
\hline $1 \mathrm{e}$ & 134 & 111.7 & 862 & 996 & 904 & 42 & 925 & 21 & 904 \\
\hline $1 f$ & 188 & 106.7 & 845 & 1033 & 874 & 29 & 958 & 25 & 933 \\
\hline $1 \mathrm{~g}$ & 84 & 33.5 & 937 & 1021 & 937 & (0) & 987 & - & - \\
\hline 5 & 234 & 218.0 & 703 & 937 & 766 & 63 & 782 & 62 & 720 \\
\hline
\end{tabular}

all values in $\mathrm{kJ} \mathrm{mol}^{-1}$.

to Eqns (1-5).

$$
\begin{gathered}
{[\mathrm{M}]^{+\cdot} \rightarrow[182]^{+}+\mathrm{X}^{\cdot}} \\
\Delta H_{\mathrm{f}}^{\prime}\left(182^{+}\right)=\Delta H_{\mathrm{f}}\left(182^{+}\right)+\varepsilon_{\mathrm{r}}^{\neq}=\mathrm{A}\left(182^{+}\right) \\
+\Delta H_{\mathrm{f}}(\mathrm{M})-\Delta H_{\mathrm{f}}\left(\mathrm{X}^{\cdot}\right) \\
\varepsilon_{\mathrm{h}}^{\neq}=\mathrm{A}\left(182^{+}\right)-\mathrm{I}(\mathrm{M}) \\
\Delta H_{\mathrm{f}}\left(\mathrm{M}^{+\cdot}\right)=\mathrm{I}(\mathrm{M})+\Delta H_{\mathrm{f}}(\mathrm{M}) \\
\Delta H_{\mathrm{f}}^{\prime}\left(182^{+}\right)_{\text {corr }}=\Delta H_{\mathrm{f}}\left(182^{+}\right)-T_{\mathrm{B}} \geq \Delta H_{\mathrm{f}}\left(182^{+}\right) \\
\Delta H_{\mathrm{R}}^{+}=\Delta H_{\mathrm{f}}\left(182^{+}\right)+\Delta H_{\mathrm{f}}\left(\mathrm{X}^{\cdot}\right)-\Delta H_{\mathrm{f}}\left(\mathrm{M}^{+*}\right)
\end{gathered}
$$

$\Delta H_{\mathrm{f}}^{\prime}(a)$ of the ion $m / z 182$ from compound 5 is calculated from the corresponding $\mathrm{A}\left(182^{+}\right)$to be $782 \pm 21 \mathrm{~kJ} \mathrm{~mol}^{-1}$. The loss of an $\mathrm{H}$ atom from the molecular ions is accompanied by a kinetic energy release $T_{\mathrm{B}}$ of $62 \mathrm{~kJ} \mathrm{~mol}^{-1}$ giving rise to a rather broad signal in the MIKE spectrum. After correction for $T_{B}$, $\Delta H_{\mathrm{f}}(a)=720 \pm 21 \mathrm{~kJ} \mathrm{~mol}^{-1}$ is obtained. This value agrees very well with $\Delta H_{\mathrm{f}}(a)=732 \pm 10 \mathrm{~kJ} \mathrm{~mol}^{-1}$ calculated independently from thermochemical data (see Appendix), and is used in the following as the true value of $\Delta H_{f}(a)$.

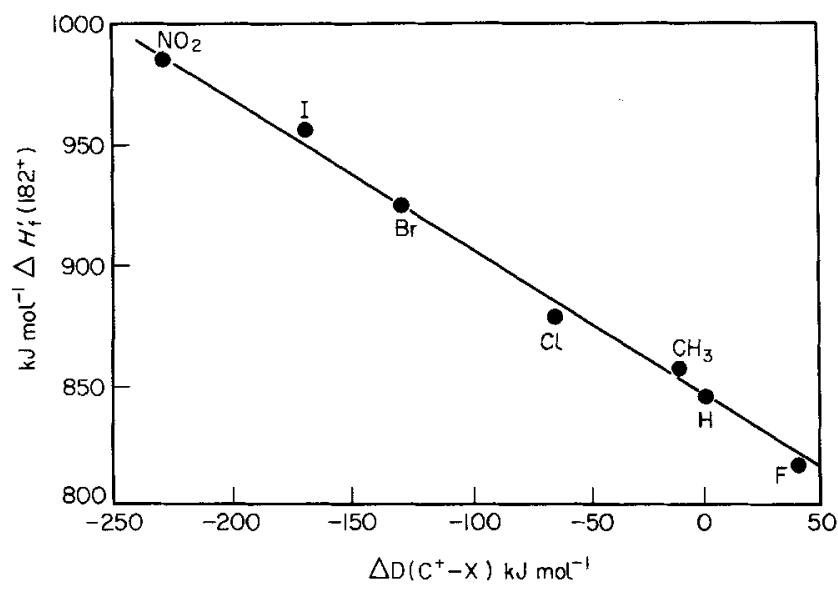

Figure 1. Dependence of apparent heats of formation on relative dissociation energies. The dissociation energy of the $\mathrm{C}-\mathrm{X}$ bond according to

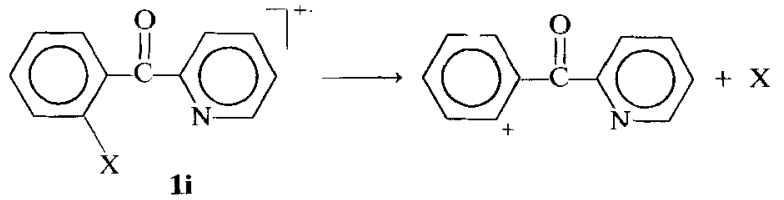

is not known, as the heat of formation of the resulting fragment ion is unknown. Hence relative dissociation energies $\triangle D\left(C^{+}-\right.$ $X)$ have been calculated, using the $\mathrm{C}-\mathrm{H}$ bond of $1 \mathrm{a}$ as a reference, as $\Delta \mathrm{D}\left(\mathrm{C}^{+}-\mathrm{X}\right)=\mathrm{D}\left(\mathrm{C}^{+}-\mathrm{X}\right)-\mathrm{D}\left(\mathrm{C}^{+}-\mathrm{H}\right)=\Delta H_{\mathrm{f}}\left(\mathrm{X}^{-}\right)$$\Delta H_{f}\left(H^{-}\right)+\Delta H_{f}\left(1 \mathbf{a}^{+\cdot}\right)-\Delta H_{f}\left(\mathbf{1 i}^{+\cdot}\right)$.

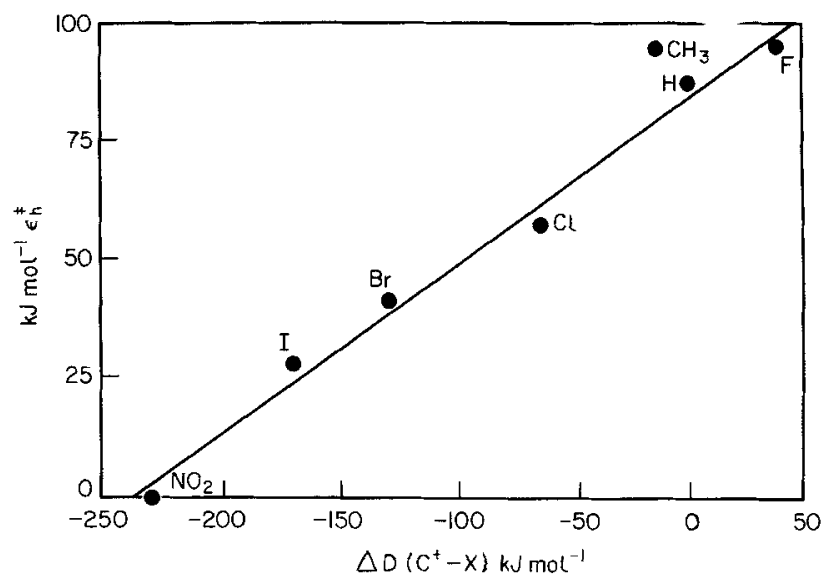

Figure 2. Dependence of activation energies on relative dissociation energies.

The apparent heats of formation $\Delta H_{\mathrm{f}}^{\prime}\left(182^{+}\right)$of the $\mathrm{m} / \mathrm{z} 182$ ions arising from the other compounds listed in Table 5 are considerably larger than that derived for ion $a$ and are not constant. This merely reflects the variation of the magnitude of the activation energy of the reverse reaction $\varepsilon_{\mathrm{r}}^{\neq}$for the individual processes. Two things should be noticed, however. At first the values of $\Delta H_{\mathrm{f}}^{\prime}\left(182^{+}\right)$rise considerably with decreasing strength of the bond cleaved during the reaction. Figure 1 shows that $\Delta H_{\mathrm{f}}^{\prime}\left(182^{+}\right)$is inversely proportional to the dissociation energy $\mathrm{D}\left(\mathrm{C}^{+}-\mathrm{X}\right)$ of that bond in the molecular ion. As has been discussed in a previous paper, ${ }^{2}$ a linear correlation between the apparent heats of formation $\Delta H_{\mathrm{f}}^{\prime}$ of an ion and the dissociation energy of the bonds broken during the reaction has to be obtained, if the same ion with a necessarily constant true heat of formation is formed by a series of reactions with constant activation energies of the forward reaction $\varepsilon_{\mathrm{h}}^{\neq}$. In the case discussed here $\varepsilon_{\mathrm{h}}^{\neq}$is not constant, as can be seen from the data of Table 5. However, a plot of $\varepsilon_{\mathrm{h}}^{\neq}$versus the dissociation energy $\mathrm{D}\left(\mathrm{C}^{+}-\mathrm{X}\right)$ reveals also a fairly good linear relation between them (Fig. 2), taking into account the possible errors in the estimation of some $I(M)$ by a Hammett plot. ${ }^{8}$ Since both $\varepsilon_{\mathrm{h}}^{\neq}$and $\Delta H_{\mathrm{f}}^{\prime}\left(182^{+}\right)$are linearly related to $\mathrm{D}\left(\mathrm{C}^{+}-\mathrm{X}\right)$, the argument still holds that the correlation observed in Fig. 1 can be found only if ions $m / z 182$ of a constant heat of formation $\Delta H_{\mathrm{f}}\left(182^{+}\right)$arise throughout the reaction series.

Second, it is of interest to note that the values of $\Delta H_{\mathrm{f}}^{\prime}\left(182^{+}\right)_{\text {corr }}$ seem to approach a constant value of $799 \mathrm{~kJ} \mathrm{~mol}^{-1}$ in cases of strongly bonded substituents. 
Table 6. Relative intensities $(\% \mathrm{~B})$ in the FI mass spectra of substituted 2-benzoyl pyridines

\begin{tabular}{crrcrccc}
\hline & $1 \mathbf{a}$ & $1 \mathbf{b}$ & $\mathbf{1 c}$ & \multicolumn{1}{c}{ 1d } & 1e & $1^{\mathrm{a}}$ & $1 \mathrm{~g}$ \\
{$[\mathrm{M}]^{2+}$} & 3 & 2 & - & 8 & 15 & - & 3 \\
{$[\mathrm{M}]^{+\cdot}$} & 100 & 100 & 100 & 12 & 10 & 10 & 5 \\
$\mathrm{~m} / \mathrm{z} 182$ & 0 & 0 & 0 & 100 & 100 & 100 & 100 \\
\hline
\end{tabular}

a Measured at elevated temperature of the $\mathrm{FI}$ emitter to avoid field condensation.

Similar behaviour has been observed for the loss of substituents from the molecular ions of benzalacetone. $^{2}$ However, in the case of the substituted 2-benzoyl pyridines $\Delta H_{f}^{\prime}\left(182^{+}\right)-T_{\mathrm{B}}$ approaches a constant value about $79 \mathrm{~kJ} \mathrm{~mol}^{-1}$ above the estimated heat of formation of ions $a$.

Taking $H_{\mathrm{f}}(a)=720 \mathrm{~kJ} \mathrm{~mol}^{-1}$, the enthalpies of reaction $\Delta H_{\mathrm{R}}^{+}$given in Table 5 are calculated. Only the loss of $\mathrm{F}$ from molecular ions of $\mathbf{1 b}$ turns out to be an endothermic reaction; those of $\mathbf{1 a}$ and $\mathbf{1 c}$ are slightly, and those of 1e-1g strongly exothermic. This explains also the very low abundances of the molecular ions of the latter compounds in the $70 \mathrm{eV}$ mass spectra, which prevented a direct determination of their $\mathrm{I}(\mathrm{M})$. In fact the measured $\mathrm{A}\left(182^{+}\right)$in the very exothermic fragmentation of $\mathbf{1 g}$ corresponds to the $\mathbf{I}(\mathbf{1 g})$, estimated from the $I(M)$ of the meta and para nitro derivatives. ${ }^{8}$ Hence there appears to be no activation energy for the loss of the nitro group from molecular ions of $\mathbf{1 g}$. The differences in $\Delta H_{\mathrm{R}}^{+}$(and in $\varepsilon_{\mathrm{h}}^{\neq}$) are reflected in the FI mass spectra of the 2-benzoyl pyridines (Table 6).

The FI mass spectra of 1a-1c contain only the base peaks of the molecular ions and small peaks due to doubly charged molecular ions. In contrast the FI mass spectra of 1d, 1e and $1 \mathrm{~g}$ show the base peak for the $[\mathrm{M}-\mathrm{X}]^{+}$ions $\mathrm{m} / \mathrm{z} 182$, and the intensity of the molecular ions is reduced to $5 \%$ in the case of $\mathbf{1 g}$.

\section{Kinetic energy release and energy partitioning}

The activation energies of the reverse reaction $\varepsilon_{\mathrm{r}}^{\neq}$and the experimentally determined kinetic energies $T$ released during the fragmentation, are listed in Table 7 for the formation of the $[\mathrm{M}-\mathrm{X}]^{+}$ions from molecular ions of 1a-1f. $\varepsilon_{\mathrm{r}}^{\neq}$has been calculated from the $\mathrm{A}\left(182^{+}\right)$and the heats of formation of $a$ and the various radicals $X$ (Table 5 ). The same data are also used to construct the potential energy diagram for this intramolecular aromatic substitution (Fig. 3). From Fig. 3 and the data of Tables 5 and 7 a rough correlation between the activation energy $\varepsilon_{\mathrm{h}}^{\neq}$and the

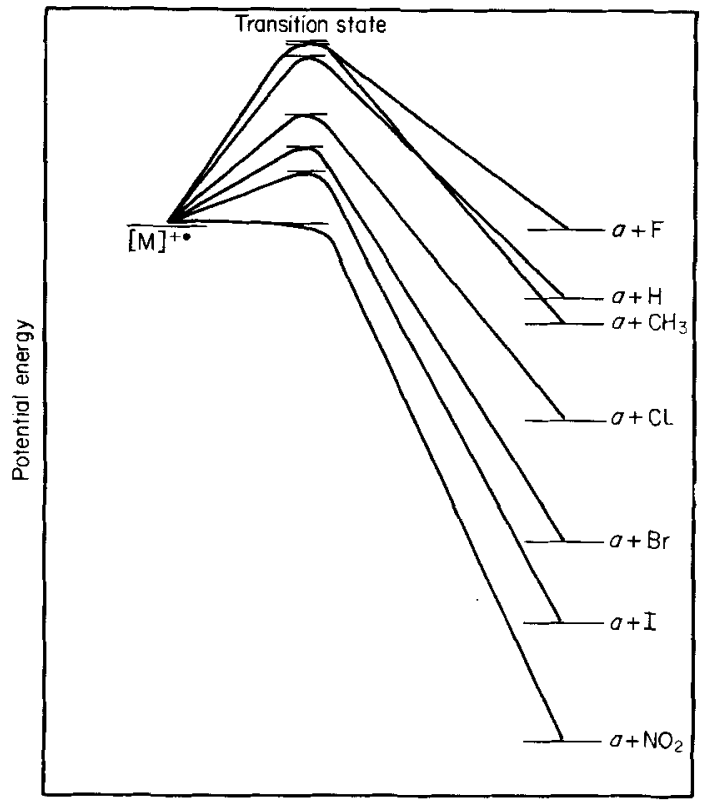

Figure 3. Potential energy diagram of intramolecular substitution in the molecular ions of $\mathbf{1 a - 1 g}$.

enthalpy $\Delta H_{\mathrm{R}}^{+}$of the fragmentation of the form $\varepsilon_{\mathrm{h}}^{\neq}=$ $101.3+0.37 \Delta H_{R}^{+}$is observed. Hence, this reaction seems to follow the Bell-Evans-Polanyi principle, ${ }^{13}$ although the effect is rather small.

A considerable $\varepsilon_{\mathrm{r}}^{\neq}$is found for every reaction of the series, even in the case of $\mathbf{1 b}$, where an F atom is lost in an endothermic process. $\varepsilon_{\mathrm{r}}^{\neq}$increases as expected with decreasing $\mathrm{D}\left(\mathrm{C}^{+}-\mathrm{X}\right)$ and is very large for the reactions of 1 and 1 g. Surprisingly neither the magnitude nor the variation of $\varepsilon_{\mathrm{r}}^{\neq}$is reflected in the values measured for $T$. Only during the loss of $\mathrm{H}$ and $\mathrm{CH}_{3}$ from the molecular ions of $\mathbf{1 a}$ and $\mathbf{1 c}$ respectively, larger values for $T$ are observed. In both cases the signals for the daughter ions $\mathrm{m} / \mathrm{z} 182$ in the MIKE spectra are broad and deviate clearly from a shape expected for a Gaussian distribution of individual $T$ 's, which would give a ratio $T_{22} / T_{55}$ of $2.16 .{ }^{14} \mathrm{In}$ all other cases $T$ is small and the signals are approximately Gaussian shaped. As a consequence the energy partitioning quotient $q$ of the excess energies of the transition states of the reactions remains small throughout the series, even if it is calculated by the aid of the maximum values $T_{\mathrm{B}}\left(q=T_{\mathrm{B}} / \varepsilon_{\mathrm{r}}^{\neq}\right)$. This is in contrast to the intramolecular aromatic substitution reaction of ortho substituted benzalacetones, ${ }^{2}$ where $\varepsilon_{\mathrm{r}}^{\neq}$is completely released $(q=0.9-1.0)$ as kinetic energy during the loss of $\mathrm{H}, \mathrm{F}$ and $\mathrm{CH}_{3}$ substituents in endothermic

Table 7. Kinetic energy release and energy partitioning quotient for the fragmentation of substituted 2-benzoyl pyridines

\begin{tabular}{|c|c|c|c|c|c|c|c|c|c|c|c|}
\hline & $\Delta H_{\mathrm{P}}^{+a}$ & $\theta_{r}^{\neq a}$ & $T_{50}^{b}$ & $T_{22}^{b}$ & $T_{22} / T_{50}$ & $T_{\mathrm{B}}^{a}$ & $q$ & $x_{0}{ }^{*}$ & $\Delta H_{R^{+\prime a}}^{+0}$ & $q^{\prime}$ & $x_{0}{ }^{\prime *}$ \\
\hline $1 \mathbf{a}$ & -38 & 126 & 227 & 391 & 1.41 & 46 & 0.37 & 0.42 & +42 & 1.0 & 0.68 \\
\hline $1 \mathrm{~b}$ & +4 & 96 & 33 & 64 & 1.94 & 13 & 0.13 & 0.53 & +79 & 0.8 & 0.89 \\
\hline $1 c$ & -50 & 146 & 267 & 380 & 1.42 & 46 & 0.31 & 0.40 & +29 & 0.7 & 0.61 \\
\hline $1 d$ & -100 & 158 & 49 & 95 & 1.94 & 13 & 0.08 & 0.27 & -21 & 0.16 & 0.44 \\
\hline $1 e$ & -163 & 205 & 66 & 145 & 2.20 & 21 & 0.10 & 0.17 & -84 & 0.17 & 0.26 \\
\hline $1 f$ & -205 & 234 & 75 & 155 & 2.07 & 25 & 0.10 & 0.12 & -126 & 0.16 & 0.18 \\
\hline $1 \mathrm{~g}$ & -268 & - & - & - & - & - & - & - & -188 & - & - \\
\hline
\end{tabular}

${ }^{\mathrm{a}} \mathrm{kJ} \mathrm{mol}^{-1}{ }^{\mathrm{b}} \mathrm{meV}$. 
or only slightly exothermic reactions. There is, however, a sudden decrease in $q$ by a factor of three if $\mathrm{Cl}$, $\mathrm{Br}, \mathrm{I}$ or $\mathrm{NO}_{2}$ are lost from the molecular ions of the substituted benzalacetones. ${ }^{2}$ It is of interest to note that a similar decrease in $q$ is also observed in the reaction studied here with $\mathrm{H}$ and $\mathrm{CH}_{3}$ as substituents on one side and $\mathrm{Cl}, \mathrm{Br}$ and $\mathrm{I}$ on the other side.

According to Miller's quantification ${ }^{3}$ of the Hammond postulate ${ }^{15}$ the position $X_{0}^{*}$ of the transition state of an elementary reaction on the reaction coordinate can be expressed by the barrier height $U^{*}$ (here $\varepsilon_{\mathrm{h}}^{\neq}$) and potential energy of the reaction $U_{\mathrm{f}}$ (here $\Delta H_{\mathrm{R}}^{+}$) according to Eqn (6).

$$
X_{0}^{*}=\frac{1}{2-U_{\mathrm{f}} / U^{*}}=\frac{1}{2-\Delta H_{\mathrm{R}}^{+} / \varepsilon_{\mathrm{h}}^{\neq}}
$$

Applying Eqn (6) to the reaction series studied shows that $X_{0}^{*}$ ranges from 0.53 to 0.12 (Table 7 ), so that symmetrical or rather 'early' transition states are involved. Again it is of interest to note that the change in the energy partitioning quotient $q$ occurs at similar values of $X_{0}^{*}$ in the intramolecular substitution reactions of the molecular ions of substituted benzalacetones $^{2}$ and of substituted 2-benzoylpyridines. With the former substances $q$ drops from 0.9 for $\mathrm{X}=\mathrm{CH}_{3}$ and $X_{0}^{*}=0.46$ to 0.2 for $\mathrm{X}=\mathrm{Cl}$ and $X_{0}^{*}=0.31$; with the latter compounds $q$ changes from 0.31 for $X=$ $\mathrm{CH}_{3}$ and $X_{0}^{*}=0.40$ to 0.1 for $\mathrm{X}=\mathrm{Cl}$ and $X_{0}^{*}=0.27$.

Thus, in spite of the individual properties of both reactions, and with the exception of the mass spectrometric behaviour of the fluoro derivative $\mathbf{1 b}$ discussed below, there are certainly common characteristics which indicate a great similarity in the mechanism and elementary reaction steps of these intramolecular substitutions. In both reaction series a larger amount of the excess energy of the transition state or $\varepsilon_{\mathrm{r}}^{\neq}$is channelled into kinetic energy of the products only if the transition state is rather 'late' $\left(X_{0}^{*} \geq 0.4\right)$ and most of the available energy has been used to stretch the bond broken in the reaction. If this bond is weak and the transition state position is 'early' on the reaction coordinate $\left(X_{0}^{*} \leq 0.4\right)$, only a small amount of the available energy in the transition state appears as kinetic energy of the products and most of it is distributed into the internal energy of the fragments.

It is puzzling that the reaction leading to the loss of the fluoro substituent from molecular ions of $\mathbf{1 b}$ does not follow the rules discussed above. By its $X_{0}^{*}=0.53$ the value of $q$ should be about 0.35 , corresponding to a kinetic energy release of $33 \mathrm{~kJ} \mathrm{~mol}^{-1}$ instead of $13 \mathrm{~kJ} \mathrm{~mol}^{-1}$. Hence the $[\mathrm{M}-\mathrm{F}]^{+}$ions $m / z 182$ should be energetically excited and decompose easily. However, metastable $[\mathrm{M}-\mathrm{F}]^{+}$ions behave as though being deprived of excess energy (see p. 124), and much of the excess energy in the $[\mathrm{M}-\mathrm{F}]^{+}$ions appears not to be available for further fragmentation reactions. Indeed, the mass spectrum of $\mathbf{1 b}$ (Table 1) contains only a few ions of low intensities derived from the $[\mathrm{M}-\mathrm{F}]^{+}$ ions.

It should be remembered also that $\Delta H_{\mathrm{f}}^{\prime}\left(182^{+}\right)-T_{\mathrm{B}}$ adjusts itself to a value of $799 \mathrm{~kJ} \mathrm{~mol}^{-1}, 79 \mathrm{~kJ} \mathrm{~mol}^{-1}$ above the estimated $\Delta H_{\mathrm{f}}(a)$ of $720 \mathrm{~kJ} \mathrm{~mol}^{-1}$. Furthermore, this energy gap of $79 \mathrm{~kJ} \mathrm{~mol}^{-1}$ is important for the mass spectrometric behaviour of the ortho substituted 2-benzoyl pyridines. Thus, formation of [M$X]^{+}$ions $m / z 182$ in the FI mass spectra is observed only if the exothermicity of the reaction (calculated with $\Delta H_{\mathrm{f}}(a)=720 \mathrm{~kJ} \mathrm{~mol}^{-1}$ ) exceeds this value (Table 6). A simple explanation for these observations would be that the estimated $\Delta H_{\mathrm{f}}(a)$ of $720 \mathrm{~kJ} \mathrm{~mol}^{-1}$ is too low and that it is in fact $799 \mathrm{~kJ} \mathrm{~mol}^{-1}$. Indeed, if this value is accepted (leading to an increase of $\Delta H_{\mathrm{R}}^{+}$and a decrease of $\varepsilon_{\mathrm{r}}^{\neq}$in Table 7 by $79 \mathrm{~kJ} \mathrm{~mol}^{-1}$ ), the resulting values for $q$ and $X_{0}^{*}$ (listed as $q^{\prime}$ and $X_{0}^{\prime *}$ in Table 7) fit even better to the model developed for energy partitioning during intramolecular aromatic substitution in molecular ions. The losses of $\mathrm{H}, \mathrm{F}$ and $\mathrm{CH}_{3}$ from 1a-1c would correspond to endothermic reactions with $X_{0}^{* *}=0.9-0.6$ and $q^{\prime}=0.7-1.0$, while the other reactions are still exothermic with $X^{\prime *}=0.44-$ 0.18 and $q^{\prime}=0.3-0.2$.

However, we hesitate to accept this explanation for two reasons. First, a value of $799 \mathrm{~kJ} \mathrm{~mol}^{-1}$ lies above the uncorrected $\Delta H_{\mathrm{f}}^{\prime}(a)$, which is derived directly from the experimental $\mathrm{A}\left(182^{+}\right)$of ions formed by 5 and which should be the upper limit of $\Delta H_{\mathrm{f}}(a)$. Second, in the formation of $[\mathrm{M}-\mathrm{X}]^{+}$ions from ortho substituted 1-phenyl-1-pyridyl-ethylenes and 2-stilbazoles, which are closely related to the compounds studied here and which will be discussed in two forthcoming papers, the heats of formation of the $[\mathrm{M}-\mathrm{X}]^{+}$ions determined experimentally by $\mathrm{A}(\mathrm{M}-\mathrm{X})^{+}$and correction for $T_{\mathrm{B}}$ and by calculations using the increments of the appendix, culminate at the same values within a few $\mathrm{kJ} \mathrm{mol}^{-1}$. This lends some credence to $\Delta H_{\mathrm{f}}\left(182^{+}\right)=720 \mathrm{~kJ} \mathrm{~mol}^{-1}$ calculated in the Appendix.

At this time we cannot offer an explanation of why the rather large amount of $79 \mathrm{~kJ} \mathrm{~mol}^{-1}$ of the potential energy of the transition state appears to be 'locked' during the formation of ions $a$. This is probably a special feature of the reaction system discussed in this paper and may be connected with the presence of the carbonyl group in ions $a$.

\section{EXPERIMENTAL}

The mass spectra of all compounds were measured on a Varian MAT 311A mass spectrometer, using direct insertion of the samples into the ion source with sample temperature $15-60^{\circ} \mathrm{C}$ and the following instrumental conditions: electron energy, $70 \mathrm{eV}$; ion source pressure $<2 \times 10^{-6}$ Torr; emission current, $2 \mathrm{~mA}$; analyser pressure $<10^{-6}$ Torr; ion source temp., $150^{\circ} \mathrm{C}$.

The MI spectra were obtained from the same instrument under similar instrumental conditions, using the DADI technique, ${ }^{16}$ i.e. scanning the potential of the electrostatic analysator at fixed values of the accelerating voltage and the magnetic field.

The kinetic energy release $T$ during the fragmentations has been calculated from the width of the signal of the appropriate decomposition in the MI spectra, corrected for the width of the main beam. ${ }^{17}$

The FI mass spectra were obtained using the MAT $311 \mathrm{~A}$ mass spectrometer after installation of a combined $\mathrm{EI} / \mathrm{FI}$ ion source using activated wire emitters 
Table 8. Melting points of substituted 2-benzoyl pyridines

\begin{tabular}{lll}
\hline & Yield & \multicolumn{1}{c}{ m.p. $\left({ }^{\circ} \mathrm{C}\right)$} \\
1b & $60 \%$ & $40-41$ \\
1c & $50 \%$ & $70-71$ \\
1d & $50 \%$ & $53-54$ \\
1e & $45 \%$ & $63-63.5$ \\
1f & $30 \%$ & $85-86$ \\
4 & $54 \%$ & $42-43$ \\
\hline
\end{tabular}

$(\mathrm{W}, 10 \mu)$. The potential difference between emitter and the counter electrode was $7.5 \mathrm{kV}$ and the emitter was heated by a current of $5 \mathrm{~mA}$. The samples were introduced as during $\mathrm{EI}$ mass spectrometry.

The ionization and appearance energies were calculated from semi-log plots ${ }^{18}$ of the ionization efficiency curves of the ions studied and the molecular ions of $\mathrm{CH}_{3} \mathrm{I}$ (I(M) $9.53 \mathrm{eV}^{12 \mathrm{~b}}$ ). These curves were measured on a modified ${ }^{4}$ Vacuum Generators MM 12B mass spectrometer by simultaneous introduction of the sample and $\mathrm{CH}_{3} \mathrm{I}$. The values given in the tables are the mean of at least three independent determinations. The reproducibility was better than $0.1 \mathrm{eV}$.

The CA spectra were obtained using a Vacuum
Generators ZAB-2F mass spectrometer by introducing air into the collision cell of the 2nd FFR until the intensity of the main beam was reduced to $30 \%$ of its original value.

2-Benzoyl pyridine (1a), 3-benzoyl pyridine (2) and 4-benzoyl pyridine (3) are commercially available (E. Merck AG, Darmstadt). The substituted 2-benzoyl pyridines (1b-1f) were obtained by oxidizing the corresponding carbinol with active $\mathrm{MnO}_{2}$ in ether. The substituted phenyl pyridyl carbinols were synthesized by the reaction of 2-pyridyl lithium with the correspondingly ortho substituted benzaldehydes according to a procedure given in the literature. ${ }^{19}$ Yields and melting points are given in Table 8 .

The ortho nitro derivative (1g) was obtained according to literature. ${ }^{20}$ 2-Pentadeuterobenzoyl pyridine (4) was synthesized starting from pentadeuterobenzaldehyde. The deuterium content, calculated from low voltage mass spectra, was $96 \% d_{5}$ and $4 \% d_{4}$.

\section{Acknowledgements}

This work is part of the research project Universität Bielefeld $\mathrm{OZ}$ 2141. We would like to thank the Fonds der Chemischen Industrie for financial support.

\section{REFERENCES}

1. Mechanism of mass spectrometric fragmentation reactions XXV. Part XXIV: H. F. Grützmacher and R. Schubert, Org. Mass Spectrom. 14, 567 (1979).

2. B. Schaldach and H. F. Grützmacher, Int. J. Mass Spectrom. Ion Phys. 31, 257 (1979).

3. A. R. Miller, J. Am. Chem. Soc. 100, 1984 (1978).

4. B. Schaldach and H. F. Grützmacher, Int. J. Mass Spectrom. Ion Phys. 31, 271 (1979).

5. J. Ronayne, D. H. Williams and J. H. Bowie, J. Am. Chem. Soc. 88, 4980 (1966).

6. U. Herzig, K. Varmuza and P. Krenmayr, Monatsh. Chem. 108, 191 (1977)

7. H. F. Grützmacher, H. Kuschel and P. Adamietz, Adv. Mass Spectrom. 5, 654 (1971).

8. (a) P. Adamietz, Diplomarbeit, University of Hamburg (1970); (b) R. Schubert, Dissertation, University of Bielefeld (1977).

9. (a) T. W. Shannon and F. W. McLafferty, J. Am. Chem. Soc. 88, 5021 (1966); (b) R. G. Cooks, J. H. Beynon, R. M. Caprioli and G. R. Lester, Metastable Ions, Elsevier, Amsterdam (1973).

10. (a) W. F. Haddon and F. W. McLafferty, J. Am. Chem. Soc. 90, 4745 (1968); (b) K. R. Jennings, Int. J. Mass Spectrom. Ion Phys. 1, 227 (1968).

11. C. R. Hurt and N. Filipescu, J. Am. Chem. Soc. 94, 3649 (1972).

12. (a) S. W. Benson, F. R. Cruickshank, D. M. Golden, G. R. Haugen, H. E. O'Neal, A. S. Rodgers, R. Shaw and R. Walsh, Chem. Rev. 69, 279 (1969); (b) H. M. Rosenstock, K. Drax!, B. W. Steiner and J. T. Herron, J. Phys. Chem. Ref. Data 6, Suppl. No. 1 (1977).
13. M. G. Evans and M. Polanyi, J. Chem. Soc. Faraday Trans. 32, 1340 (1936).

14. J. F. Elder Jr, J. H. Beynon and R. G. Cooks, Org. Mass Spectrom. 11, 415 (1976).

15. G. S. Hammond, J. Am. Chem. Soc. 77, 334 (1955).

16. (a) K. H. Maurer, C. Brunnée, G. Kappus, K. Habfast, U. Schröder and P. Schulze, American Society for Mass Spectrometry, 19th Annual Conference on Mass Spectrometry and Allied Topics, Atlanta, Georgia (1971); (b) J. H. Beynon and R. G. Cooks, Res. Dev. 22, 26 (1971).

17. M. A. Baldwin, P. J. Derrick and R. P. Morgan, Org. Mass Spectrom. 11, 440 (1976).

18. F. P. Lossing, A. W. Tickner and W. A. Bryce, J. Chem Phys. 19, 1254 (1951).

19. H. Gilman and S. M. Spatz, J. Org. Chem. 16, 1485 (1951).

20. A. J. Nunn and K. Schofield, J. Chem. Soc. 583 (1952).

21. B. S. Freiser and J. L. Beauchamp, J. Am. Chem. Soc. 98, $265(1976)$.

22. J. A. Kerr, Chem. Rev. 66, 465 (1966)

23. R. H. Staley, M. Taagepera, W. G. Henderson, I. Koppel, J. L. Beauchamp and R. W. Taft, J. Am. Chem. Soc. 99, 326 (1977).

24. S. K. Pollach, J. L. Develin, K. D. Summerhags, R. W. Taft and N. J. Hehre, J. Am. Chem. Soc. 99, 4583 (1977).

Received 27 June 1979; accepted 22 August 1979

(C) Heyden \& Son Ltd, 1980

\section{APPENDIX}

\section{Estimation of $\Delta H_{\mathrm{f}}(a)$ by thermochemical data}

$\Delta H_{f}(a)$ can be calculated independently by the following hypothetical reaction sequence and the corresponding enthalpy changes of the reaction steps:

$$
\begin{aligned}
\mathbf{P A}(\mathbf{1 a}) & =\Delta H_{\mathrm{f}}(\mathbf{1 a})+\Delta H_{\mathrm{f}}\left(\mathrm{H}^{+}\right)-\Delta H_{\mathrm{f}}(x) \\
\mathrm{D}(\stackrel{+}{\mathrm{N}}-\mathrm{H}) & =\Delta H_{\mathrm{f}}(y)+\Delta H_{\mathrm{f}}\left(\mathrm{H}^{*}\right)-\Delta H_{\mathrm{B}}(x) \\
\mathrm{D}\left(\mathrm{C}_{\mathrm{ar}}-\mathrm{H}\right) & =\Delta H_{\mathrm{f}}(z)+\Delta H_{\mathrm{f}}\left(\mathrm{H}^{*}\right)-\Delta H_{\mathrm{B}}(y) \\
\mathrm{D}(\stackrel{+}{\mathrm{N}}-\mathrm{Ph}) & =\Delta H_{\mathrm{f}}(z)-\Delta H_{\mathrm{f}}(a)
\end{aligned}
$$


<smiles>O=C(c1ccccc1)c1ccccn1</smiles>

$1 \mathrm{a}$<smiles></smiles>

$x$<smiles>C[14c]1cc[nH+]c(C(=O)c2ccccc2)c1</smiles>

$y$<smiles></smiles>

Combination of Eqns (A1-A4) results in Eqn (A5):

$$
\begin{aligned}
\Delta H_{\mathrm{f}}(a)= & \Delta H_{\mathrm{f}}(1 a)-2 \Delta H_{\mathrm{f}}\left(\mathrm{H}^{\cdot}\right)+\Delta H_{\mathrm{f}}\left(\mathrm{H}^{+}\right)-\mathrm{PA}(\mathbf{1 a}) \\
& +\mathrm{D}\left(\mathrm{C}_{\mathrm{ar}}-\mathrm{H}\right)-[\mathrm{D}(\stackrel{+}{\mathrm{N}}-\mathrm{Ph})-\mathrm{D}(\stackrel{+}{\mathrm{N}}-\mathrm{H})]
\end{aligned}
$$

$\Delta H_{\mathbf{f}}(\mathbf{1 a})=100 \mathrm{~kJ} \mathrm{~mol}^{-1}$ has been calculated from increments, ${ }^{12 \mathrm{a}} \Delta H_{\mathrm{f}}\left(\mathrm{H}^{\circ}\right)=218 \mathrm{~kJ} \mathrm{~mol}^{-1}$ and $\Delta H_{\mathrm{f}}\left(\mathrm{H}^{+}\right)=$ $1528 \mathrm{~kJ} \mathrm{~mol}^{-1}$ are known accurately. ${ }^{12 \mathrm{~b}} \mathrm{PA}$ (1a) cor- responds to the proton affinity of a benzoyl substituted pyridine, which will not deviate greatly from the PA (pyridine) $=916 \mathrm{~kJ} \mathrm{~mol}^{-121}$ because of the small Hammett constant of a benzoyl substituent of $\sigma_{\mathrm{p}}=-0.05$. $\mathrm{D}\left(\mathrm{C}_{\mathrm{ar}}-\mathrm{H}\right)=435 \mathrm{~kJ} \mathrm{~mol}^{-1}$ is the homolytic dissociation energy of the $\mathrm{C}-\mathrm{H}$ bond in benzene. ${ }^{22}$

However, no values are known for the homolytic dissociation energies $\mathrm{D}(\stackrel{+}{\mathrm{N}}-\mathrm{H})$ and $\mathrm{D}(\stackrel{+}{\mathrm{N}}-\mathrm{Ph})$ in the pyridinium ion and $N$-phenyl pyridinium ion. Fortunately, only the difference between both dissociation energies has to be estimated. If one accepts the reasonable assumption that this difference will be the same for $x$ and $a$ as for other aminium ions, it can be calculated with the aid of reactions (A6) and (A7) and $\Delta H_{\mathrm{f}}(\mathrm{Ph})=301 \mathrm{~kJ} \mathrm{~mol}^{-1}, \Delta H_{\mathrm{f}}(\mathrm{H})=218 \mathrm{~kJ} \mathrm{~mol}^{-1}$, $\Delta H_{\mathrm{f}}\left(\left(\mathrm{CH}_{3}\right)_{2} \mathrm{NH}\right)=-18.8 \mathrm{~kJ} \mathrm{~mol}^{-1},{ }^{12 \mathrm{a}} \Delta \mathrm{H}_{\mathrm{f}}\left(\left(\mathrm{CH}_{3}\right)_{2} \mathrm{NPh}\right)$ $=95.4 \mathrm{~kJ} \mathrm{~mol}^{-1},{ }^{12 \mathrm{a}} \mathrm{PA}\left(\left(\mathrm{CH}_{3}\right)_{2} \mathrm{NH}\right)=911.3 \mathrm{~kJ} \mathrm{~mol}^{-123}$ and $\mathrm{PA}\left(\left(\mathrm{CH}_{3}\right)_{2} \mathrm{NPh}\right)=920 \mathrm{~kJ} \mathrm{~mol}^{-1.24}$

$$
\begin{gathered}
\left(\mathrm{CH}_{3}\right)_{2} \stackrel{+}{\mathrm{N}} \mathrm{H}_{2} \rightarrow\left(\mathrm{CH}_{3}\right)_{2} \stackrel{+}{\mathrm{N}} \dot{\mathrm{H}}+\mathrm{H}^{\cdot} \\
\left(\mathrm{CH}_{3}\right)_{2} \stackrel{+}{\mathrm{N}} \mathrm{HPh} \rightarrow\left(\mathrm{CH}_{3}\right)_{2} \stackrel{+}{\mathrm{N}} \dot{\mathrm{H}}+\mathrm{Ph}
\end{gathered}
$$

$$
\begin{aligned}
& \mathrm{D}(\stackrel{+}{\mathrm{N}}-\mathrm{H})-\mathrm{D}(\stackrel{+}{\mathrm{N}}-\mathrm{Ph}) \\
&=\left[\Delta \mathrm{H}_{\mathrm{f}}\left(\mathrm{H}^{\cdot}\right)-\Delta \mathrm{H}_{\mathrm{f}}(\mathrm{Ph})\right]-\left[\Delta \mathrm{H}_{\mathrm{f}}\left(\left(\mathrm{CH}_{3}\right)_{2} \mathrm{NH}\right)\right. \\
&\left.-\Delta \mathrm{H}_{\mathrm{f}}\left(\left(\mathrm{CH}_{3}\right)_{2} \mathrm{NPh}\right)\right]+\left[\mathrm{PA}\left(\left(\mathrm{CH}_{3}\right)_{2} \mathrm{NH}\right)\right. \\
&\left.-\mathrm{PA}\left(\left(\mathrm{CH}_{3}\right)_{2} \mathrm{NPh}\right)\right] \\
&= 21 \mathrm{~kJ} \mathrm{~mol}^{-1}
\end{aligned}
$$

Insertion of the appropriate values into Eqn (A5) results in $\Delta H_{\mathrm{f}}(a)=732 \mathrm{~kJ} \mathrm{~mol}^{-1}$. 